\title{
Suppressive Effect of Polyphenols from the Seed Coat of Scarlet Runner Beans on Blood Glucose Levels
}

\author{
Zhaohong Ci ${ }^{1,2}$, Chengyu Jiang ${ }^{1,2}$, Michiyuki Kojima ${ }^{2,3, *}$ \\ ${ }^{1}$ Department of Food Production Science, Obihiro University of Agriculture and Veterinary Medicine, 11, Nishi-2-sen, Inada-machi, \\ Obihiro, Hokkaido 080-8555, Japan \\ ${ }^{2}$ United Graduate School of Agricultural Sciences, Iwate University, 3-18-8, Ueda, Morioka, Iwate 020-8550, Japan \\ ${ }^{3}$ Department of Human Sciences, Obihiro University of Agriculture and Veterinary Medicine, 11, Nishi-2-sen, \\ Inada-machi, Obihiro, Hokkaido 080-8555, Japan \\ *Corresponding author: kojima@obihiro.ac.jp
}

\begin{abstract}
Scarlet runner beans (SRB) are a valuable source of many nutrients, including proteins, starch, dietary fiber, and oligosaccharides, and are used in various foods in Japan. In this study, we analyzed their polyphenol and procyanidin contents, DPPH radical scavenging activity, and reducing power. SRB (purple) had a higher polyphenol content and DPPH radical scavenging activity than those of SRB (black). The reducing power of SRB (black) (5.1 $\mathrm{mg} / \mathrm{g}$ ) was greater than that of SRB (purple) $(4.1 \mathrm{mg} / \mathrm{g}$ ). Both SRB (purple) and SRB (black) had greater levels of polymeric polyphenols (total Fra.II and Fra.III) than monomeric polyphenols (Fra.I), and inhibited the activity of $\alpha$-glucosidase in a dose-dependent manner. SRB (black) showed higher $\alpha$-glucosidase inhibitory activity $\left(\mathrm{IC}_{50}, 26.4 \mu \mathrm{g} / \mathrm{mL}\right.$ ) than that of SRB (purple) $\left(\mathrm{IC}_{50}, 39.7 \mu \mathrm{g} / \mathrm{mL}\right.$ ), and a mixed pattern of inhibition (non-competitive and uncompetitive). The $\alpha$-glucosidase inhibitory activity was greater for polyphenols from the seed coat $(>91 \%)$ than from the cotyledon $(<0.1 \%$ ) for SRB (purple) and SRB (black). Both $250 \mathrm{mg} / \mathrm{kg}$ and $750 \mathrm{mg} / \mathrm{kg}$ polyphenols from the coat of SRB (purple) effectively suppressed the elevation of blood glucose levels after the oral administration of starch in mice. These results suggest that the seed coat of SRB has useful properties and, in particular, has potential applications for the treatment of diabetes.
\end{abstract}

Keywords: scarlet runner bean, seed coat, polyphenol, $\alpha$-glucosidase, blood glucose

Cite This Article: Zhaohong Ci, Chengyu Jiang, and Michiyuki Kojima, "Suppressive Effect of Polyphenols from the Seed Coat of Scarlet Runner Beans on Blood Glucose Levels." Journal of Food and Nutrition Research, vol. 6, no. 3 (2018): 182-186. doi: 10.12691/jfnr-6-3-7.

\section{Introduction}

Diabetes has received considerable attention owing to the increasing number of people suffering from this chronic disease [1]. Postprandial hyperglycemia is an important risk factor for the development of Type II diabetes [2]. Controlling the blood glucose level is the most effective method for preventing diabetes deterioration and hyperglycemia [3]. All dietary carbohydrates are hydrolyzed by enzymes to yield simple sugars, which can improve blood glucose levels [4]. $\alpha$-Glucosidase is an intestinal cell membrane enzyme that can hydrolyze polysaccharides; hence, inhibiting the activity of $\alpha$ glucosidase may be an effective way to treat pre-diabetes and slow the progression of diabetes [5].

Several synthetic $\alpha$-glucosidase inhibitors, such as acarbose and voglibose, have been developed, but these have various side effects, such as digestion disorders, flatulence, and liver function disorders [6]. Recently, many studies have focused on natural $\alpha$-glucosidase inhibitors from plants. Although it has been reported that polyphenolic compounds from legumes $[7,8]$ could inhibit $\alpha$-glucosidase activity, few studies have examined the inhibitory activity of these polyphenolic compounds on both $\alpha$-glucosidase and blood glucose levels.

In the present study, we examined the inhibitory effects of polyphenols from scarlet runner beans (SRB) (Phaseolus coccineus L.) on $\alpha$-glucosidase in vitro. Moreover, we evaluated the effect of polyphenols from the coat of SRB (purple) on blood glucose levels after the oral administration of starch in mice in vivo.

\section{Materials and Methods}

\subsection{Materials}

SRB (purple) have black spots on a purple surface, and SRB (black) are purely black. Samples of SRB (purple) and SRB (black) were purchased from the Kawanishi Agricultural Cooperative Association (Obihiro, Japan). Diaion HP-20 columns and Sephadex LH-20 columns for chromatography were obtained from the Mitsubishi Chemical Corporation (Tokyo, Japan) and GE Healthcare Bio-Sciences AB (Uppsala, Sweden), respectively. All other reagents and chemicals were purchased from Wako Pure Chemical Industries, Ltd. (Osaka, Japan), unless stated otherwise. 


\subsection{Extract Preparation and Fractionation}

SRBs were ground into a powder, followed by extraction with $20 \mathrm{~mL}$ of $80 \%$ ethanol. After ultrasound treatment for $30 \mathrm{~min}$, the mixture was centrifuged at $1,006 \times g$ for $10 \mathrm{~min}$ to obtain a supernatant. The same extraction process was repeated two more times. The residues were subjected to another three rounds of extraction with $70 \%$ acetone and the supernatant. Then, the supernatant was mixed, concentrated by rotary evaporation in a vacuum, and purified by chromatography through Diaion HP-20 columns. The columns were washed with distilled water and then eluted with methanol. The methanol solution was concentrated by rotary evaporation in a vacuum, and dissolved in $2 \mathrm{~mL}$ of methanol for the experiment. Part of the concentrate was dissolved in ethanol and fractionated by Sephadex LH-20 column chromatography. The column was successively eluted with ethanol, methanol, and $60 \%$ acetone to collect fraction I (Fra.I), fraction II (Fra.II), and fraction III (Fra.III), respectively.

\subsection{Quantification of Polyphenols}

Polyphenols were quantified using the Folin-Ciocalteu method [9]. The methanol fraction (HP-20 column) (100 $\mu \mathrm{L}$ ) was treated with $300 \mu \mathrm{L}$ of distilled water, $400 \mu \mathrm{L}$ of Folin-Ciocalteu reagent, and $400 \mu \mathrm{L}$ of a $10 \% \mathrm{Na}_{2} \mathrm{CO}_{3}$ solution. The mixture was prepared in triplicate, incubated at $30{ }^{\circ} \mathrm{C}$ for $30 \mathrm{~min}$, and centrifuged at $1,006 \times \mathrm{g}$ for 10 min. The absorbance of the mixed supernatant was measured at $760 \mathrm{~nm}$. The polyphenol content is expressed in $\mathrm{mg}$ of catechin equivalents per gram of beans $(\mathrm{mg} / \mathrm{g})$.

\subsection{Quantification of Procyanidins}

The procyanidin content of the methanol fraction (HP20 column) was determined by the HCl-butanol method [10], using cyanidin as the standard equivalent.

\subsection{Estimation of DPPH Radical Scavenging Activity}

DPPH radical scavenging activity was evaluated by the method described by Brand-Williams et al. [11], with some modifications. A $50-\mu \mathrm{L}$ aliquot of the sample was mixed with $100 \mu \mathrm{L}$ of ethanol, and the mixture was supplemented with $150 \mu \mathrm{L}$ of $0.5 \mathrm{mM}$ DPPH in ethanol. The absorbance of the mixture was measured using a microplate reader at $517 \mathrm{~nm}$. The DPPH radical scavenging activity is expressed in $\mu \mathrm{mol}$ trolox equivalents per gram of beans $(\mu \mathrm{mol} / \mathrm{g})$.

\subsection{Estimation of Reducing Power}

Reducing power was evaluated according to a previously reported method, with minor modifications [12]. Briefly, $250 \mu \mathrm{L}$ of the methanol fraction (HP-20 column) was mixed with $250 \mu \mathrm{L}$ of sodium phosphate buffer ( $\mathrm{pH} 7.5)$ in a test tube, and $250 \mu \mathrm{L}$ of $1 \%(\mathrm{w} / \mathrm{v})$ potassium ferricyanide was added. The mixture was incubated at $50^{\circ} \mathrm{C}$ for $20 \mathrm{~min}$. After the incubation period, $250 \mu \mathrm{L}$ of $10 \%$ trichloroacetic acid was added and centrifuged at
$1,006 \times g$ for $10 \mathrm{~min}$. The upper layer of the supernatant $(500 \mu \mathrm{L})$ was mixed with $500 \mu \mathrm{L}$ of distilled water and $100 \mu \mathrm{L}$ of $0.1 \%(\mathrm{w} / \mathrm{v})$ ferric chloride, and reacted under shading for $15 \mathrm{~min}$. The absorbance of the reaction mixture was measured at $700 \mathrm{~nm}$. Reducing power activity is expressed in $\mathrm{mg}$ of vitamin $\mathrm{C}$ equivalent per gram of beans $(\mathrm{mg} / \mathrm{g})$.

\section{7. $\alpha$-Glucosidase Inhibitory Activity}

$\alpha$-Glucosidase inhibition was analyzed following the methods of Matsumoto et al. [13], with modifications. Sucrose was broken down by $\alpha$-glucosidase, and the amount of reducing sugar was calculated based on the $\alpha$ glucose content. In total, $0.8 \mathrm{~mL}$ of the enzyme reaction solution $(50 \mu \mathrm{L}$ of $0.4 \%$ sucrose, $625 \mu \mathrm{L}$ of $0.1 \mathrm{~mol} / \mathrm{L}$ sodium phosphate buffer ( $\mathrm{pH} 6.8$ ), and $125 \mu \mathrm{L}$ of $1 \%$ $\mathrm{NaCl}$ ) was pre-incubated at $37{ }^{\circ} \mathrm{C}$ for $30 \mathrm{~min}$. The methanol fraction (HP-20 column) (polyphenol concentration, $0-100 \mu \mathrm{g} / \mathrm{mL}$ ) was added to $0.1 \mathrm{U} / \mathrm{mL} \alpha$-glucosidase solution (EC3.2.1.20; Oriental Yeast Co., Ltd., Tokyo, Japan) at $37{ }^{\circ} \mathrm{C}$ for $10 \mathrm{~min}$. After pre-incubation, $200 \mu \mathrm{L}$ of the mixture (polyphenol extract and $\alpha$-glucosidase) was added to the enzyme reaction solution and incubated at $37{ }^{\circ} \mathrm{C}$ for $30 \mathrm{~min}$. The reaction was terminated by adding $125 \mathrm{~mL}$ of $2 \mathrm{M} \mathrm{NaOH}$, and $1 \%$ dinitrosalicylic acid was added in boiling water for $10 \mathrm{~min}$. After incubation, the mixture was analyzed at $540 \mathrm{~nm}$ at room temperature. Enzyme inhibitory reactions, for all polyphenol extract concentrations, were replicated three times. The $\alpha$ glucosidase inhibitory activity is expressed as the percent inhibition. The concentration of inhibitors required for the inhibition of $50 \%$ of the enzyme activity under the assay conditions was defined as the $\mathrm{IC}_{50}$ value.

The inhibitory kinetics of $\alpha$-glucosidase by the polyphenol extract was determined by the Lineweaver-Burk equation. Sucrose was used as the substrate in the concentration range of 3.3-20.0 mM. The enzyme activity was measured at 0 and $10 \mu \mathrm{g} / \mathrm{mL}$ polyphenols.

\subsection{Oral Starch Tolerance Test in Mice}

Male DDY mice (Japan SLC, Inc., Shizuoka, Japan) were housed in plastic cages at $23^{\circ} \mathrm{C}$, a $12 \mathrm{~h} / 12 \mathrm{~h}$ light/dark cycle, and a relative humidity of $60 \%$. Mice had free access to feed (CE-2; CLEA Japan, Inc., Tokyo, Japan) and water for 1 week before the experiment. The feed had $344.9 \mathrm{kcal} / 100 \mathrm{~g}$ and contained (w/w \%) $24.9 \%$ crude protein, $4.6 \%$ crude fat, $4.1 \%$ crude fiber, $6.6 \%$ crude ash, $51.0 \%$ NFE (nitrogen-free extract), and $8.9 \%$ moisture. After 1 week, the animals were randomly divided into experimental groups ( 8 mice per group). The mice were fasted for $24 \mathrm{~h}$ and blood was withdrawn from the tail vein and subjected to assays of blood glucose levels. The polyphenols from SRB (purple) were suspended in physiological solution and used doses of 250 and 750 $\mathrm{mg} / \mathrm{kg}$. After the oral administration of the suspension of polyphenolic compounds for $30 \mathrm{~min}$, a single oral injection of $2 \mathrm{~g} / \mathrm{kg}$ starch in physiological solution was administered. Blood was withdrawn from the tail vein at $0.5,1$, and $2 \mathrm{~h}$, and blood glucose levels were analyzed using the OMRON Precision Exceed HEA-216 (Omron Healthcare Co., Ltd., Kyoto, Japan) according to the 
manufacturer's instructions. The study was approved by the regulatory authority of the National University Corporation Obihiro University of Agriculture and Veterinary Medicine and it adhered to the standard principles described in the Guide for the Care and Use of Laboratory Animals.

\subsection{Statistical Analysis}

Values are presented as the means \pm standard error of 5 out of 8 mice in each group. 5 mice in each group. Statistical significance was evaluated by ANOVA and least significant difference (LSD) tests (SAS Enterprise Guide 5.1 system). Differences were considered significant when $p<0.05$.

\section{Results and Discussion}

\subsection{Polyphenol and Procyanidin Content, DPPH Radical Scavenging Activity, and Reducing Power}

Table 1 summarizes the polyphenol and procyanidin contents, DPPH radical scavenging activity, and reducing power for SRB (purple) and SRB (black). The polyphenol contents were 9.9 and $7.6 \mathrm{mg} / \mathrm{g}$ and the DPPH radical scavenging activities were 41.7 and $39.3 \mu \mathrm{mol} / \mathrm{g}$ for SRB (purple) and SRB (black), respectively. SRB (purple) showed a higher polyphenol content and DPPH radical scavenging activity than those of SRB (black) $(\mathrm{p}<0.05)$. A positive correlation between the polyphenol content and DPPH radical scavenging activity for common beans has been reported by $\mathrm{Ci}$ et al. [14]. Polyphenols from the coat and cotyledon of SRB (purple) and SRB (black) were analyzed. Polyphenol ratios were higher for the coat $(>96 \%)$ than for the cotyledon $(<4 \%)$. The cotyledon contains the main reserve of substances, particularly proteins and carbohydrates. The seed coat, which acts as a protective barrier for the cotyledon, has a high concentration of phenolic compounds $[15,16]$. The procyanidin contents were 3.9 and $3.8 \mathrm{mg} / \mathrm{g}$ for SRB (purple) and SRB (black). The reducing power was greater for SRB (black) $(5.1 \mathrm{mg} / \mathrm{g})$ than for SRB (purple) $(4.1 \mathrm{mg} / \mathrm{g})$.

\subsection{Polyphenol Fractions}

We performed Sephadex LH-20 column chromatography obtain three polyphenol fractions, i.e., Fra.I, Fra.II, and Fra.III, for each SRB (Figure 1). Fra.I represented 24\% and $13 \%$, and the total values of Fra.II and Fra.III were $76 \%$ and $87 \%$ for SRB (purple) and SRB (black), respectively.

According to Saito et al. [7], Fra.I contains monomeric polyphenols, and Fra.II and Fra.III contain polymeric polyphenols. Both SRB (purple) and SRB (black) had higher ratios of polymeric polyphenols than monomeric polyphenols.

\section{3. $\alpha$-Glucosidase Inhibitory Activity}

We analyzed the inhibitory effects of polyphenols on $\alpha$ glucosidase. Polyphenols from both SRB (purple) and SRB (black) inhibited the activity of $\alpha$-glucosidase in a dose-dependent manner. Phenolic compounds from seven kinds of legume [7], soybeans [8], and the millet seed coat [17] inhibit $\alpha$-glucosidase activity. SRB (black) showed greater $\alpha$-glucosidase inhibitory activity $\left(\mathrm{IC}_{50}, 26.4 \mu \mathrm{g} / \mathrm{mL}\right)$ than that of SRB (purple) $\left(\mathrm{IC}_{50}, 39.7 \mu \mathrm{g} / \mathrm{mL}\right)$ (Table 1). SRB (black) showed greater percentages of Fra.II and Fra.III (Figure 1), and a high degree of polymeric polyphenols exhibits stronger $\alpha$-glucosidase inhibitory activity than that of monomeric phenolic compounds. We also analyzed the inhibitory effects of polyphenols $(20 \mu \mathrm{g} / \mathrm{mL})$ on $\alpha$-glucosidase for the seed coat and cotyledon of SRB (purple) and SRB (black). $\alpha$-Glucosidase inhibitory activity levels of $91 \%$ and $94 \%$ were observed for the seed coat of SRB (purple) and SRB (black), and both were less than $0.1 \%$ for the cotyledon. We speculate a much higher degree of polymeric polyphenols in the seed coat than the cotyledon results in stronger $\alpha$-glucosidase inhibitory activity.

Table 1. Summary of polyphenols, procyanidins, DPPH radical scavenging activity, reducing power, and inhibition of $\alpha$-glucosidase for scarlet runner beans

\begin{tabular}{|c|c|c|c|c|}
\hline & Polyphenols (mg/g) & DPPH radical scavenging activity $(\mu \mathrm{mol} / \mathrm{g})$ & Reducing power (mg/g) & $\begin{array}{l}\alpha \text {-Glucosidase inhibitory activity } \\
\operatorname{IC}_{50}(\mu \mathrm{g} / \mathrm{mL})\end{array}$ \\
\hline SRB (purple) & $9.9^{\mathrm{a}} \pm 0.1$ & $3.9^{\mathrm{a}} \pm 0.1$ & $41.7^{\mathrm{a}} \pm 0.7$ & 39.7 \\
\hline SRB (black) & $7.6^{\mathrm{b}} \pm 0.2$ & $3.8^{\mathrm{a}} \pm 0.0$ & $39.3^{b} \pm 0.3$ & 26.4 \\
\hline
\end{tabular}

Values followed by different letters in a column are significantly different $(p<0.05)$.

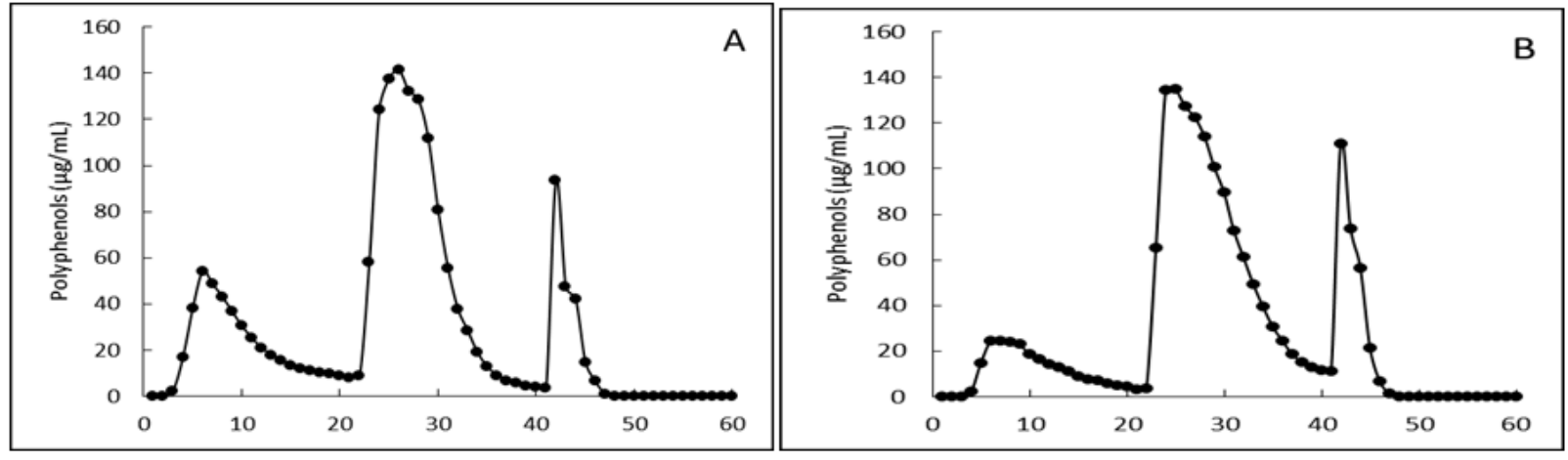

Figure 1. Scarlet runner bean polyphenols were applied to the LH-20 column for the successive elution of Fra.I (ethanol fraction, 1-20), Fra.II (methanol fraction, 21-40), and Fra.III (60\% Acetone fraction, 41-60). A. SRB (purple), B. SRB (black) 
We also performed an enzyme kinetic study of $\alpha$-glucosidase inhibition. Figure 2 shows a Lineweaver-Burk plot of the $\alpha$-glucosidase inhibitory activity of polyphenols from SRB (black) at 0 and $10 \mu \mathrm{g} / \mathrm{mL}$, with different concentrations of sucrose $(3.3-20.0 \mathrm{mM})$. The maximum velocity $\left(V_{\max }\right)$ was $0.59 \mathrm{mmol} / \mathrm{min}$ and the Michaelis-Menten constant $\left(K_{\mathrm{m}}\right)$ was $20.6 \mathrm{mM}$ for sucrose. When the concentration of polyphenols was $10 \mu \mathrm{g} / \mathrm{mL}, V_{\max }$ increased to $0.7 \mathrm{mmol} / \mathrm{min}$, and $K_{\mathrm{m}}$ increased to $31.8 \mathrm{mM}$. In the presence of polyphenols from SRB (black), both $V_{\max }$ and $K_{\mathrm{m}}$ increased, implying that polyphenols exhibited a mixed type of inhibition towards $\alpha$-glucosidase, i.e., noncompetitive and uncompetitive inhibition. It has been reported that the structural factors of phenolic groups are crucial determinants of the inhibitory pattern of polyphenols on $\alpha$-glucosidase [4]. In our study, both SRB (purple) and SRB (black) had higher levels of polymeric polyphenols than monomeric polyphenols. We speculate that polyphenols from SRB (purple) also have a mixed pattern of $\alpha$-glucosidase inhibition. Different natural compounds have different inhibition patterns against $\alpha$ glucosidase; for example, finger millet (Eleusine coracana L.) seed coat phenolics exhibit noncompetitive inhibition [17], and three flavonoids (quercetin, isoquercetin, and rutin) exhibit mixed noncompetitive and anticompetitive inhibition [18].

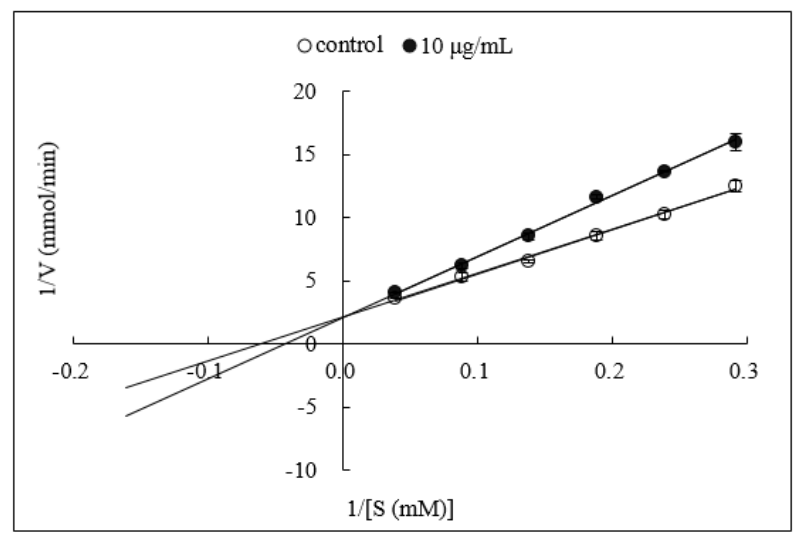

Figure 2. Lineweaver-Burk plots of polyphenols against $\alpha$-glucosidase for SRB (black)

\subsection{Inhibitory Effects of Polyphenols on Blood Glucose Levels after Oral Administration of Starch}

Compared with those in the cotyledon, polyphenols of the seed coat of SRB (purple) showed more effective inhibition against $\alpha$-glucosidase in vitro. The polyphenols from the seed coat of SRB (purple) were tested for their inhibitory effects on the elevation of blood glucose levels by the oral starch tolerance test in mice. After the administration of starch, the maximum increase in the blood glucose level was observed at $30 \mathrm{~min}$ in all mice, but mice treated with $250 \mathrm{mg} / \mathrm{kg}$ and $750 \mathrm{mg} / \mathrm{kg}$ polyphenols exhibited significantly lower blood glucose concentrations than those of the control group $(p<0.01)$ (Figure $3 \mathrm{~A}$ ). At $60 \mathrm{~min}$, the $250 \mathrm{mg} / \mathrm{kg}$ and $750 \mathrm{mg} / \mathrm{kg}$ polyphenol groups still showed significantly lower glucose levels than those of the control group $(p<0.05)$. At $120 \mathrm{~min}$, the blood glucose concentrations recovered to the levels observed at 0 min. SRB (black) was similar to SRB (purple) with respect to the polyphenol distribution and $\alpha$-glucosidase inhibitory activity; accordingly, we speculated that SRB (black) also can effectively reduce blood glucose in vivo. Polyphenols from kidney beans [19] and black beans [20] also reduce blood glucose in rats.
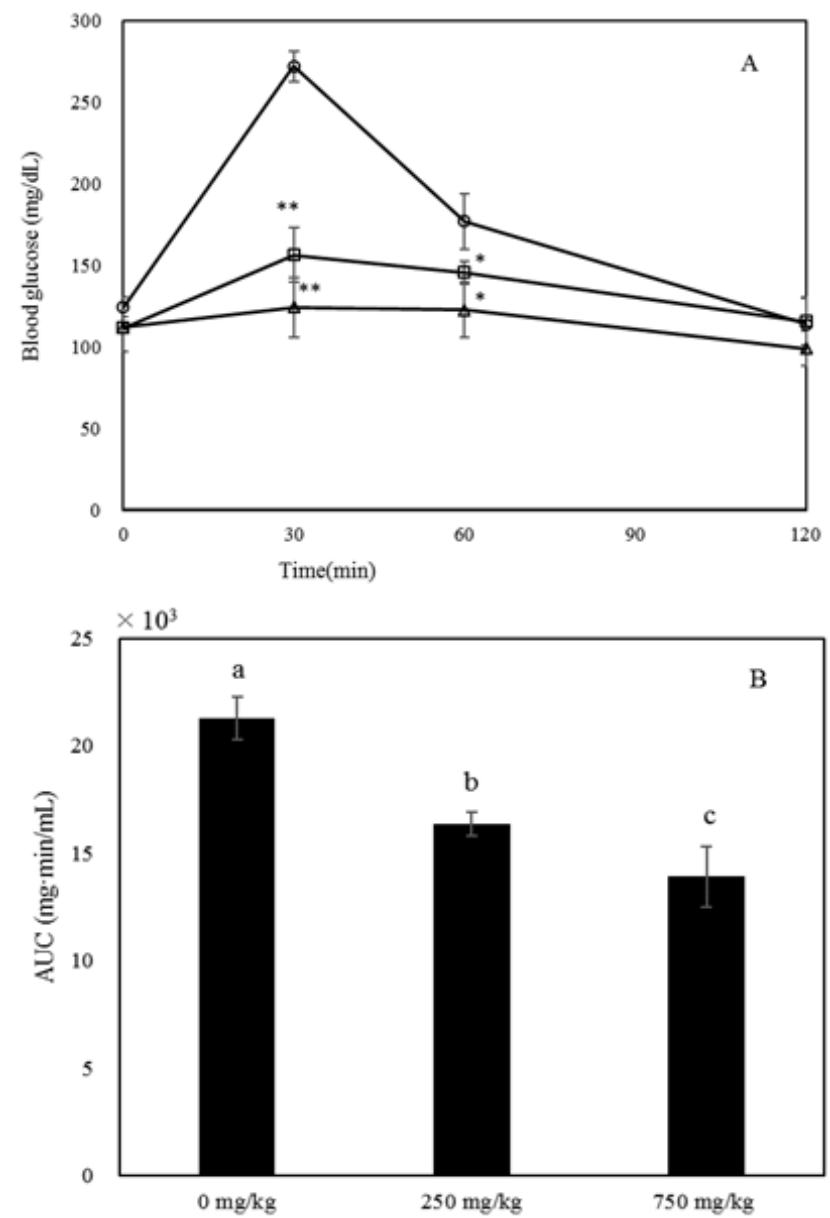

Figure 3. Oral starch tolerance test to monitor the inhibitory effect of polyphenols from SRB (purple) on blood glucose levels in mice (A) and AUC values (B). Values are presented as the means \pm standard error of 5 mice per group. $*$ indicates a significant difference with respect to the control $(* * p<0.01, * p<0.05)$. Symbols: $\bigcirc, 0 \mathrm{mg} / \mathrm{kg} ; \square, 250 \mathrm{mg} / \mathrm{kg}$; $\triangle, 750 \mathrm{mg} / \mathrm{kg}$ mouse. Values followed by different letters in a column are significantly different $(p<0.05)$

The area under the curve (AUC) of the blood glucose level over a 120 -min period is shown in Figure $3 \mathrm{~B}$. The AUC value was significantly lower for the $750 \mathrm{mg} / \mathrm{kg}$ polyphenol group than for the other groups, and was significantly lower for the $250 \mathrm{mg} / \mathrm{kg}$ group than for the control group.

\section{Conclusions}

SRB (purple) had a higher polyphenol content and DPPH radical scavenging activity than those of SRB (black). Both SRB (purple) and SRB (black) showed high ratios of polymeric polyphenols and inhibited the activity of $\alpha$-glucosidase in a dose-dependent manner. Moreover, polyphenols from the seed coat of SRB (purple) effectively suppressed the elevation of blood glucose levels in vivo, as shown by experiments of the oral 
administration of starch in mice. These observations indicate that the seed coat of SRB may serve as a source for the development of nutraceuticals with anti-diabetic activity.

\section{Acknowledgements}

We acknowledge the financial support provided by the Obihiro University of Agriculture and Veterinary Medicine, as well as Iwate University.

\section{Statement of Competing Interests}

The authors have no competing interests.

\section{List of Abbreviations}

AUC: area under the curve DPPH: 2,2-diphenyl-1-picrylhydrazyl

LSD: least significant difference

SRB: scarlet runner beans

\section{References}

[1] Cohen, P., Goedert, M, "GSK3 inhibitors: development and therapeutic potential," Nature Reviews Drug Discovery, 3(6). 479-487. June 2004.

[2] Dong, H.Q., Li, M., Zhu, F., Liu, F.L., Huang, J.B, "Inhibitory potential of trilobatin from Lithocarpus polystachyus Rehd against $\alpha$-glucosidase and $\alpha$-amylase linked to type 2 diabetes," Food Chemistry, 130. 261-266. January 2012.

[3] Mertes, G, "Safety and efficacy of acarbose in the treatment of Type 2 diabetes: Data from a 5-year surveillance study," Diabetes Research and Clinical Practice, 52. 193-204. June 2001.

[4] Xiao, H.Z., Liu, B.G., Mo, H.Z., Liang, G.Z, "Comparative evaluation of tannic acid inhibiting $\alpha$-glucosidase and trypsin," Food Research International, 76. 605-610. October 2015.

[5] Baron, A.D, "Postprandial hyperglycaemia and alpha-glucosidase inhibitors," Diabetes Research and Clinical Practice, 40. 51-55. July 1998.

[6] Hollander, P, "Safety profile of acarbose, an alpha-glucosidase inhibitor," Drugs, 44 (Suppl. 3). 47-53. 1992.

[7] Saito, Y., Nishi, S., Koaze, H., Hironaka, K., Kojima, M., "Antioxidant and inhibitory activity on $\alpha$-amylase and $\alpha$ glucosidase in legume polyphenols," Nippon Shokuhin Kagaku Kogaku Kaishi, 54(12). 563-567. 2007.
[8] Adedayo O. Ademiluyia, Ganiyu Oboh, "Soybean phenolic-rich extracts inhibit key-enzymes linked to type 2 diabetes $(\alpha$-amylase and $\alpha$-glucosidase) and hypertension (angiotensin I converting enzyme) in vitro," Experimental and Toxicologic Pathology, 65. 305-309. March 2013.

[9] Miyashita, J., Nishi S., Saito Y., Koaze, H., Hironaka, K. and Kojima, M, "Annual variations in the anthocyanin contents of blueberry fruit grown in Hokkaido," Research Bulletin of Obihiro University of Agriculture and Veterinary Medicine, 28. 35-40. 2007.

[10] Takahata, Y., Ohnishi-Kameyama, M., Furuta, S., Takahashi, M., Suda, I, "Highly polymerized procyanidins in brown soybean seed coat with a high radical-scavenging activity," Journal of Agricultural and Food Chemistry, 49(12). 5843-5847. December 2001.

[11] Brand-Williams, W., Cuvelier, M.E. and Berset, C, "Use of a free radical method to evaluate antioxidant activity," LebensmittelWissenschaft und Technologie, 28. 25-30. 1995.

[12] Oyaizu, M., "Studies on products of browning reaction prepared from glucosamine," Japanese Journal of Nutrition, 44. 307-315. April 1986.

[13] Matsumoto, N., Ishigaki,A ,. Iwashina, H. and Hara, Y, "Reduction of blood glucose levels by tea catechin," Bioscience, Biotechnology, Biochemistry, 57. 525-527. 1993.

[14] Ci, Z. H., Jiang, C. Y., Tsukamoto, C., Kojima, M, "DPPH radical scavenging activity and polyphenols in the pods of 3 common beans," Journal of Food and Nutrition Research, 5. 12. 900-907. November 2017.

[15] Shahidi, F., Chavan, U.D., Naczk, M., Amarowicz, R, "Nutrient distribution and phenolic antioxidants in air-classified fractions of beach pea (Lathyrus maritimus L.)," Journal of Agricultural and Food Chemistry, 49. 926-933. February 2001.

[16] Troszynska, A., Bednarska, A., Latosz, A., Kozlowska, H, "Polyphenolic compounds in the seed coat of legume seeds," Polish Journal of Food Nutrition Science, 6. 37-45. 1997.

[17] Shobana, S., Sreerama, Y.N., Malleshi, N.G, "Composition and enzyme inhibitory properties of finger millet (Eleusine coracana $L$.) seed coat phenolics: mode of inhibition of $\alpha$-glucosidase and pancreatic amylase," Food Chemistry, 115. 1268-1273. August 2009.

[18] Li, Y.Q., Zhou, F.C., Gao, F., Bian, J.S., Shan, F, “Comparative evaluation of quercetin, isoquercetin and rutin as inhibitors of alpha-glucosidase," Journal of Agricultural and Food Chemistry, 57. 11463-11468. December 2009.

[19] Fantini, N., Cabras, C., Lobina, C., Colombo, G., Gessa, G.L., Riva, A., Donzelli, F., Morazzoni, P., Bombardelli, E., Carai, M.A "Reducing effect of a Phaseolus vulgaris dry extract on food intake, body weight, and glycemia in rats," Journal of Agricultural and Food Chemistry, 57. 9316-9323. October 2009.

[20] Carai, M.A., Fantini, N., Loi, B., Colombo, G., Gessa, G.L., Riva, A., Bombardelli, E.; Morazzoni, P, "Multiple cycles of repeated treatments with a Phaseolus vulgaris dry extract reduce food intake and body weight in obese rats," British Journal of Nutrition, 106. 762-768. May 2011. 